BIO Web of Conferences 2, 03003 (2014)

DOI: $10.1051 /$ bioconf/ 20140203003

C) Owned by the authors, published by EDP Sciences, 2014

\title{
Cometary micrometeorites and input of prebiotic compounds
}

\author{
C. Engrand ${ }^{1}$
}

${ }^{1}$ CSNSM CNRS/IN2P3-Univ. Paris Sud, Bat. 104, 91405 Orsay Campus, France

\begin{abstract}
The apparition of life on the early Earth was probably favored by inputs of extraterrestrial matter brought by carbonaceous chondrite-like objects or cometary material. Interplanetary dust collected nowadays on Earth is related to carbonaceous chondrites and to cometary material. They contain in particular at least a few percent of organic matter, organic compounds (amino-acids, PAHs,...), hydrous silicates, and could have largely contributed to the budget of prebiotic matter on Earth, about $4 \mathrm{Ga}$ ago. A new population of cometary dust was recently discovered in the Concordia Antarctic micrometeorite collection. These "Ultracarbonaceous Antarctic Micrometeorites" (UCAMMs) are dominated by deuterium-rich and nitrogen-rich organic matter. They seem related to the "CHON" grains identified in the comet Halley in 1986. Although rare in the micrometeorites flux ( $<5 \%$ of the micrometeorites), UCAMMs could have significantly contributed to the input of prebiotic matter. Their content in soluble organic matter is currently under study.
\end{abstract}

\section{Introduction}

Interplanetary dust originating from asteroids and comets could have contributed to the origin of life on Earth [e.g.1; 2 and references therein]. They could have brought prebiotic material that was used to favor the origin of life on Earth. Cosmic dust also seeded other planetary bodies where life could have emerged as well, such as Mars, Titan, Europa or Enceladus...

The origin of interplanetary dust is dual, from asteroids and comets [e.g. 3; 4; 5]. To understand the differences between cometary and asteroidal material, we need to investigate samples that are representative of interplanetary material. The analysis of micrometeorites (MMs), which are submillimetric dust particles recovered on the Earth surface in the size range of $\sim 20$ to $300 \mu \mathrm{m}$, can contribute to this issue. Micrometeorites represent the dominant input of extraterrestrial matter on Earth nowadays. With the logistic support of the French and Italian polar institutes IPEV \& PNRA, we collect them in Antarctic ice and snow in very clean conditions. We have shown that micrometeorites represent a new population of extraterrestrial matter: they are related to the primitive meteorites, the carbonaceous chondrites, but also show differences (size and abundance of minerals, isotopic composition of hydrogen... [e.g. 6; 7;8]. Chondritic micrometeorites contain hydrous minerals and about $2 \mathrm{wt} \%$ of carbonaceous matter [6;9]. Their contents in carbonaceous matter and in volatile elements are especially interesting for an input of prebiotic matter on the primitive Earth. A new population of ultracarbonaceous particles discovered in the Concordia Antarctic micrometeorite collection is also considered as an interesting vector of prebiotic material. 


\section{Interplanetary dust as representative sampling of interplanetary matter}

For the following reasons, micrometeorites could represent a less biased sample of interplanetary matter than meteorites:

- The dynamical evolution of cosmic dust in interplanetary space is less biased than that of meteorites. It is dominated by non-gravitational forces like Poynting-Robertson drag [10], whereas meteorites are delivered to Earth as a result of interactions with resonances, and their accretion is biased through gravitational focusing by the Earth [11].

- The high proportion of carbonaceous-chondrite like objects (related to C-type asteroids) in the cosmic dust population $(>80 \%$ [e.g. $6 ; 7 ; 8 ; 12])$ better agrees with the proportions of C-type (> $55 \%)$ over S-type $(<20 \%)$ asteroids [13]) than that in the meteorite collections $(\sim 5 \%)$. The proportion of C-type asteroids in the main asteroid belt is currently revisited and could in fact dominate the asteroid population and provide a better match to the characteristics of MMs [14 and personal communication]. The meteorite collections under-represent the carbonaceous chondrites (CC) with regard to ordinary chondrites (linked to S-type asteroids [15-18]), as these fragile CC meteorites may be preferentially destroyed during atmospheric entry and by weathering at the Earth's surface before recovery (e.g. [19]).

- There are evidences of an invariance of the composition of the flux of micrometeorites as a function of time [20-23] or toward smaller sizes [24; 25].

On the other hand, recent dynamical models propose a preferential formation of large amounts of dust from Jupiter family comets that could explain the high abundance of carbonaceous-chondritelike objects in the micrometeorite collections [5; 26]. This work would thus imply that most (if not all) micrometeorites with sizes $<500 \mu \mathrm{m}$ are of cometary origin. This in turn would not contradict the relationship of micrometeorites with carbonaceous chondrite-like objects, as cometary material returned from the STARDUST mission from the Jupiter family comet Wild2 is close to that of carbonaceous chondrites as well [e.g. 27; 28]. Antarctic micrometeorites also show large similarities to Wild 2 samples [29].

\section{Search for organic matter in micrometeorites}

Chondritic micrometeorites contain a few $\mathrm{wt} \%$ of insoluble organic matter (IOM). Raman microspectroscopy and high-resolution transmission electron microscopy studies of this IOM show a primitive and very disorganized structure of this organic compound [30;31].

Soluble organic matter was searched for in micrometeorites collected from Antarctic blue ice fields at Cap-Prudhomme. They contain organic molecules such as PAHs and possibly amino acids, particularly AIB [32; 33] (Fig. 1 and Table 1). The presence of AIB in micrometeorites was confirmed by Matrajt et al. [34] (Table 2), after several negative attempts [35; 36]. However, micrometeorites analyzed to date show a contamination of amino acids from the Antarctic ice [see 32], and only non-biological amino acids (such as AIB and isovaline) can reasonably be attributed to the sample analyzed. 


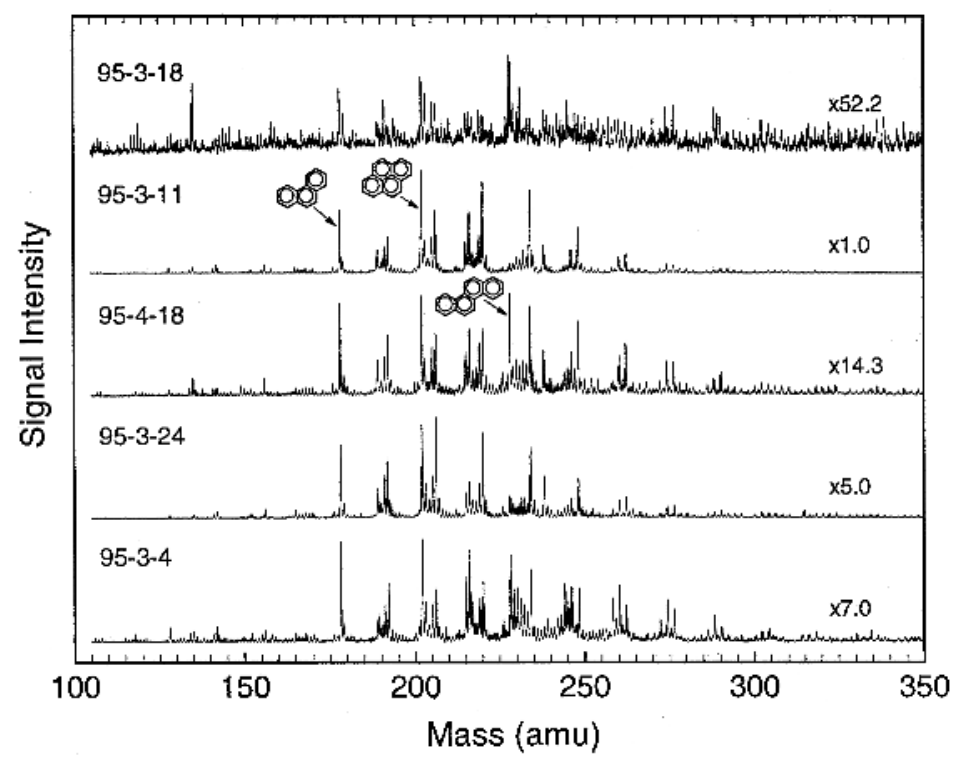

Figure 1: Spectra of PAHs detected in Cap Prud'homme Antarctic micrometeorites [from 33].

Table 1: Determination of concentrations (in ppm) of amino-acids in 5 sets of about 50 Cap Prud'homme micrometeorites [from 32].

\begin{tabular}{lccccc}
\hline Amino acid & $\begin{array}{l}\Lambda 91 \\
(50 \mu \mathrm{g})\end{array}$ & $\begin{array}{l}\mathrm{I} 91 \\
(175 \mu \mathrm{g})\end{array}$ & $\begin{array}{l}\mathrm{III} 91 \\
(310 \mu \mathrm{g})\end{array}$ & $\begin{array}{l}\text { IV94 } \\
(166 \mu \mathrm{g})\end{array}$ & $\begin{array}{l}\mathrm{V} 94 \\
(259 \mu \mathrm{g})\end{array}$ \\
\hline D-Aspartate & 10 & 1 & 18 & 20 & 20 \\
L-Aspartate & 34 & 1 & 30 & 40 & 100 \\
L-Serine & 85 & 73 & 100 & 7 & 100 \\
D,L-Glutamate & 280 & 170 & 40 & 40 & 70 \\
Glycine & 260 & 250 & 210 & 5 & 40 \\
D-Alanine & 570 & 73 & 37 & $<0.1$ & $<0.6$ \\
L-Alanine & 620 & 310 & 180 & 60 & 60 \\
AIB & 280 & 78 & 22 & $<0.1$ & 20 \\
D,L-Isovaline & $<13$ & $<3$ & $<20$ & $<0.1$ & $<1$ \\
\hline
\end{tabular}

Table 2 (top and bottom): Determination of concentrations of amino-acids in micrometeorite sample from the South-Pole Water Well (samples A, B and C) compared to that of rust grains (R1 and R2) used as blanks [from 34].

\begin{tabular}{|c|c|c|c|c|c|c|c|c|c|c|}
\hline \multirow[t]{2}{*}{ Amino acid detected } & \multicolumn{6}{|c|}{ A (MMs) $6.9 \mathrm{mg}$} & \multicolumn{4}{|c|}{$\mathrm{Rl}$ (rust grains) $4.8 \mathrm{mg}$} \\
\hline & \multicolumn{2}{|c|}{$\mathrm{H}_{2} \mathrm{O}(\mathrm{nmol} / \mathrm{g})^{\mathrm{a}}$} & \multicolumn{2}{|c|}{$\mathrm{HF}(\mathrm{nmol} / \mathrm{g})$} & \multicolumn{2}{|c|}{ Total $(\mathrm{nmol} / \mathrm{g})$} & $\mathrm{H}_{2} \mathrm{O}(\mathrm{nmol} / \mathrm{g})$ & \multicolumn{2}{|c|}{$\mathrm{HF}(\mathrm{nmol} / \mathrm{g})$} & Total $(\mathrm{nmol} / \mathrm{g})$ \\
\hline Glutamic acid & 2.3 & & \multicolumn{2}{|c|}{9.7} & 12.0 & & 2.8 & 25 & & 27.8 \\
\hline Glycine & 5.8 & & \multicolumn{2}{|c|}{46.3} & 52.1 & & 6.3 & 56.3 & & 62.6 \\
\hline Alanine & 3.3 & & \multicolumn{2}{|c|}{12.3} & 15.6 & & 7.2 & 12.5 & & 19.7 \\
\hline AIB & 0.5 & & \multicolumn{2}{|c|}{1.6} & 2.1 & & $<0.0005$ & $<0.0005$ & & - \\
\hline Valine & 0.7 & & \multicolumn{2}{|c|}{1.8} & 2.5 & & 2.1 & $<0.0005$ & & 2.1 \\
\hline Aspartic acid & n.d. & & \multicolumn{2}{|c|}{ n.d. } & - & & 1.6 & n.d. & & 1.6 \\
\hline Serine & $<0.0005$ & & \multicolumn{2}{|c|}{$<0,0005$} & - & & $\sim 3.2$ & n.d. & & $\sim 3.2$ \\
\hline \multicolumn{11}{|c|}{ nmol/g - nanomol of amino acid per gram of sample (micrometeorite or nust). } \\
\hline \multirow[t]{2}{*}{ Amino acid detected } & \multicolumn{4}{|c|}{ B (MMs) (5 mg) } & C (MMs) & $5 \mathrm{mg})$ & & R2 (rust g & ains) (2 mg & \\
\hline & $\begin{array}{l}\mathrm{H}_{2} \mathrm{O} \\
(\mathrm{nmol} / \mathrm{g})^{\mathrm{a}}\end{array}$ & $\begin{array}{l}\mathrm{HF} \\
(\mathrm{nm}\end{array}$ & $1 / g)$ & $\begin{array}{l}\text { Total } \\
(\mathrm{nmol} / \mathrm{g})\end{array}$ & $\begin{array}{l}\mathrm{H}_{2} \mathrm{O} \\
(\mathrm{nmol} / \mathrm{g})\end{array}$ & $\begin{array}{l}\mathrm{HF} \\
(\mathrm{nmol} / \mathrm{g}\end{array}$ & $\begin{array}{l}\text { Total } \\
(\mathrm{nmol} / \mathrm{g})\end{array}$ & $\begin{array}{l}\mathrm{H}_{2} \mathrm{O} \\
(\mathrm{nmol} / \mathrm{g})\end{array}$ & $\begin{array}{l}\mathrm{HF} \\
(\mathrm{nmol} / \mathrm{g})\end{array}$ & $\begin{array}{l}\text { Total } \\
(\mathrm{nmol} / \mathrm{g})\end{array}$ \\
\hline Glutamic acid & 2.5 & 216. & & 219.0 & 20.4 & 6.6 & 27.0 & 79.3 & 539.6 & 619 \\
\hline Glycine & 7.8 & 280. & & 288.4 & 34.7 & 30.1 & 64.9 & 193.5 & 675.6 & 869 \\
\hline Alanine & 5.9 & 180. & & 186.4 & 23.4 & 14.6 & 38.0 & 151.8 & 500 & 652 \\
\hline AIB & $<0.0005$ & $<0$. & 005 & - & $<0.0005$ & $<0.0005$ & - & $<0.0005$ & $<0.0005$ & - \\
\hline Valine & 2.1 & 132 & & 134.0 & 5.1 & 10.4 & 15.5 & 57.5 & 143.8 & 201 \\
\hline Aspartic acid & 2.1 & n.d. & & 2.1 & 21.1 & 13 & 34.1 & 53.2 & 394.5 & 448 \\
\hline Serine & 1.0 & n.d. & & 1.0 & 10.5 & n.d & 10.5 & 78.5 & n.d. & 78.5 \\
\hline
\end{tabular}


We recently discovered ultracarbonaceous micrometeorites (UCAMMs) in the collection of micrometeorites from Antarctic snow, in the vicinity of the Concordia Station at Dome C (Fig. 2). These particles have no counterpart in the meteorite collections. They are dominated by carbonaceous matter and have an anomalously deuterium-rich hydrogen isotopic composition. UCAMMs contain a minor amount of minerals intimately associated with the carbonaceous matter [31]. These particles contain up to $85 \%$ of organic matter in volume (or $65 \mathrm{wt} \%$ of C), thus showing carbon contents up to 10 times that of the most C-rich carbonaceous chondrites [37-39]. Three such UCAMMs were also reported in a collection performed at Dome Fuji [40]. Such concentrations of carbonaceous matter are comparable with that of the most C-rich IDPs [41; 42], and compatible with CHON grains detected in comet Halley by the Giotto and Vega spatial missions in 1986 [43; 44].

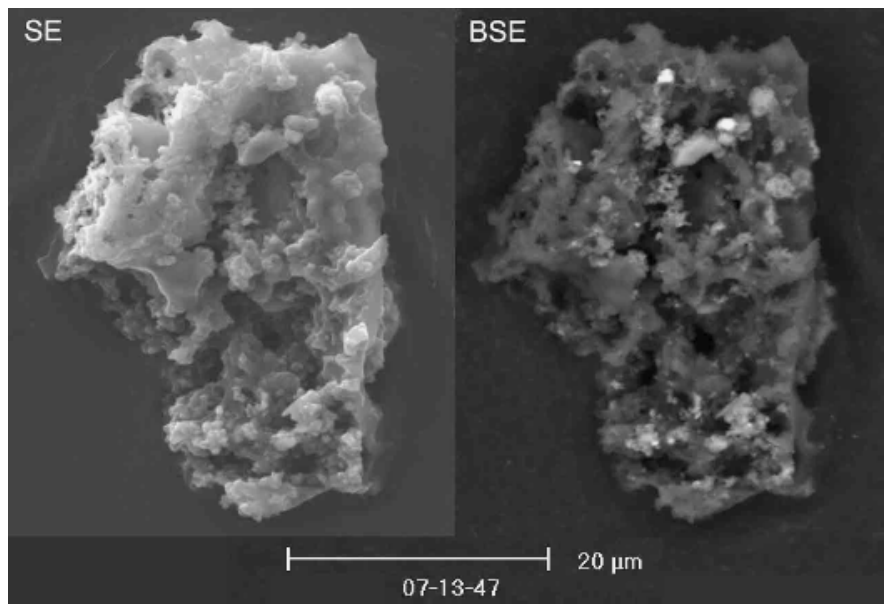

Figure 2: Backscattered electron micrograph of a fragment of CONCORDIA Ultracarbonaceous Antarctic Micrometeorite (UCAMM). All dark grey patches are constituted of organic matter. Brighter flakes are silicates or Fe-Ni sulphides.

The organic matter of UCAMMs show very high $\mathrm{D} / \mathrm{H}$ ratios, and is significantly enriched in nitrogen compared to meteorites [45-47]. Mineralogical, isotopic and spectroscopic data recently obtained on these particles indicate that they are most likely cometary grains, possibly originating from Oort Cloud comets [45; 46]. Although samples of the comet Wild2 brought back by the STARDUST mission remain the only sample of ascertain cometary origin, we can point three problems concerning the reliability of the characterization of their organic matter: (i) very small amounts material were collected, (ii) the heating during capture has altered organic matter, (iii) the aerogel collector contained detectable amounts of terrestrial contamination of organic matter.

UCAMMS provide access to organic matter of very likely cometary origin, in an unprecedented state of preservation. Concordia micrometeorites (including UCAMMs) have the advantage of having short residence times in the snow (less than 50 years) at very low temperatures ( -30 to $-80^{\circ}$ C), and in areas where life is virtually absent. They are therefore the appropriate samples to search for organics compounds like amino acids. Martin et al. [48] have developed a method for analyzing an individual particle of about 50 microns that could be tried to analyze UCAMMs. The orbitrap technique (in collaboration with R. Thissen and V. Vuitton at IPAG Grenoble) will also be tried to search for organic compounds in micrometeorites.

Acknowledgements: During her $\mathrm{PhD}$, Elena Dobrică made significant contributions in the characterization of the UCAMMs, this new family of cometary particles, in collaboration with H. 
Leroux, E. Quirico and J.-N. Rouzaud. The collect and analyses of UCAMMs are ongoing at CSNSM with J. Duprat. Michel Maurette was a pioneer in the collection and analyses of polar micrometeorites, and for their implications for the formation of the solar system and for exobiology. Gero Kurat had a crucial role in micrometeorite research. This work was supported by CNRS IN2P3, INSU (PNP), EPOV, IPEV, ANR Jeunes Chercheurs "Micromet", CNES, and FP6 RTN Marie Curie "ORIGINS".

\section{References}

1. M. Maurette, In Comets and the Origin and Evolution of Life, 69-111 (2006)

2. A. Brack, Nature Geosci. 2, 8-9 (2009)

3. E. Grün, Ann. Geophys. 13, Supp. III, C708 (1995)

4. J. Lasue, A.C. Levasseur-Regourd, N. Fray and H. Cottin, Astron. Astrophys. 473, 641-649 (2007)

5. D. Nesvorny, P. Jenniskens, H.F. Levison, W.F. Bottke, D. Vokrouhlicky and M. Gounelle, Astrophys. J. 713, 816-836 (2010)

6. C. Engrand and M. Maurette, Meteoritics Planet. Sci. 33, 565-580 (1998)

7. C. Engrand, E. Deloule, F. Robert, M. Maurette and G. Kurat, Meteoritics Planet. Sci. 34, 773787 (1999)

8. G. Kurat, C. Koeberl, T. Presper, F. Brandstätter and M. Maurette, Geochim. Cosmochim. Acta 58, 3879-3904 (1994)

9. G. Matrajt, S. Taylor, G. Flynn, D.E. Brownlee and D. Joswiak, Meteoritics Planet. Sci. 38, 1585$1600(2003)$

10. J.A. Burns, P.L. Lamy and S. Soter, Icarus 40, 1-48 (1979)

11. D. Vokrouhlický and P. Farinella, Nature 407, 606-608 (2000)

12. C. Engrand, K.D. McKeegan and L.A. Leshin, Geochim. Cosmochim. Acta 63, 2623-2636 (1999)

13. T. Mothé-Diniz, J.M.r. Carvano and D. Lazzaro, Icarus 162, 10-21 (2003)

14. F.E. DeMeo and B. Carry (2012) The bias-corrected mass distribution of compositional classes in the main asteroid belt. In AAS/Division for Planetary Sciences Meeting Abstracts.

15. D.L. Buczkowski, O.S. Barnouin-Jha and L.M. Prockter, Icarus 193, 39-52 (2008)

16. L.F. Lim and L.R. Nittler, Icarus 200, 129-146 (2009)

17. A. Fujiwara, et al., Science 312, 1330-1334 (2006)

18. T. Nakamura, et al., Lunar Planet. Sci. XLII, \#1766 (2011)

19. A. Meibom and B.E. Clark, Meteoritics Planet. Sci. 34, 7-24 (1999)

20. M. Gounelle, M.E. Zolensky, J.-C. Liou, P.A. Bland and O. Alard, Geochim. Cosmochim. Acta 67, 507-527 (2003)

21. M. Gounelle, C. Engrand, O. Alard, P.A. Bland, M.E. Zolensky, S.S. Russell and J. Duprat, Geochim. Cosmochim. Acta 69, 3431-3443 (2005)

22. C. Engrand, K.D. McKeegan, L.A. Leshin, G.F. Herzog, C. Schnabel, L.E. Nyquist and D.E. Brownlee, Geochim. Cosmochim. Acta 69, 5365-5385 (2005)

23. T. Yada, et al., Geochim. Cosmochim. Acta 69, 5789-5804 (2005)

24. M. Gounelle, C. Engrand, M. Maurette, G. Kurat, K.D. McKeegan and F. Brandstätter, Meteoritics Planet. Sci. 40, 917-932 (2005)

25. J. Aléon, C. Engrand, L.A. Leshin and K.D. McKeegan, Geochim. Cosmochim. Acta 73, 4558$4575(2009)$

26. W.F. Bottke, H.F. Levison, D. Nesvorny, A. Morbidelli and M. Gounelle (2008) The collisional evolution of objects captured in the outer asteroid belt during the late heavy bombardment. In Asteroids, Comets, Meteors, pp. \#8096, Baltimore.

27. D. Brownlee, et al., Science 314, 1711-1716 (2006)

28. T. Nakamura, et al., Science 321, 1664-1667 (2008)

29. E. Dobrică, C. Engrand, J. Duprat, M. Gounelle, H. Leroux, E. Quirico and J.N. Rouzaud, Meteoritics Planet. Sci. 44, 1643-1661 (2009) 
30. E. Dobrică, C. Engrand, E. Quirico, G. Montagnac and J. Duprat, Meteoritics Planet. Sci. 46, 1363-1375 (2011)

31. E. Dobrică, C. Engrand, H. Leroux, J.N. Rouzaud and J. Duprat, Geochim. Cosmochim. Acta 76, 68-82 (2012)

32. K.L.F. Brinton, C. Engrand, D.P. Glavin, J.L. Bada and M. Maurette, Orig. Life Evol. Biosph. 28, 413-424 (1998)

33. S.J. Clemett, X.D.F. Chillier, S. Gillette, R.N. Zare, M. Maurette, C. Engrand and G. Kurat, Orig. Life and Evol. Biosphere 28, 425-448 (1998)

34. G. Matrajt, S. Pizzarello, S. Taylor and D. Brownlee, Meteoritics Planet. Sci. 39, 1849-1858 (2004)

35. G. Matrajt, La contribution des micrométéorites à l'origine de la vie sur Terre. Ph.D. thesis thesis. Paris VI, Paris (2001)

36. D. Glavin, G. Matrajt and J.L. Bada, Adv. Space Res. 33, 106-113 (2004)

37. M.M. Grady and C.T. Pillinger, Geochim. Cosmochim. Acta 50, 255-263 (1986)

38. J.F. Kerridge, Geochim. Cosmochim. Acta 49, 1707-1714 (1985)

39. S. Pizzarello, Y. Huang, L. Becker, R.J. Poreda, R.A. Nieman, G. Cooper and M. Williams, Science 293, 2236-2239 (2001)

40. T. Nakamura, T. Noguchi, Y. Ozono, T. Osawa and K. Nagao, Meteoritics Planet. Sci. 40 Suppl., \#5046 (2005)

41. L.P. Keller, S. Messenger, G.J. Flynn, S. Clemett, S. Wirick and C. Jacobsen, Geochim. Cosmochim. Acta 68, 2577-2589 (2004)

42. K.L. Thomas, G.E. Blanford, L.P. Keller, W. Klöck and D. McKay, Geochim. Cosmochim. Acta 57, 1551-1566 (1993)

43. J. Kissel and F.R. Krueger, Nature 326, 755-760 (1987)

44. M.E. Lawler and D.E. Brownlee, Nature 359, 810-812 (1992)

45. J. Duprat, et al., Science 328, 742-745 (2010)

46. E. Dartois, et al., Icarus 224, 243-252 (2013)

47. G. Briani, C. Engrand, J. Duprat, R. Benoit, H. Krueger, H. Fischer, M. Hilchenbach, C. Briois and L. Thirkell (2012) TOF-SIMS Analyses of an Ultracarbonaceous MicroMeteorite: preparation of Rosetta-COSIMA studies in 2014. In Lunar Planet. Sci., pp. \#2584.

48. M.P. Martin, D.P. Glavin and J.P. Dworkin, Lunar Planet. Sci. XXXIX, \#2055 (CD-ROM) (2008) 